\title{
V
}

\section{A POPULARIZAÇÃO DA CIÊNCIA NO BRASIL: OBJETIVOS E CONCEPÇÕES NOS EDITAIS DE FOMENTO DO CNPQ*}

\author{
Cleiton da Silva Pinheiro \\ Romulo Ramunch Mourão Silva
}

\section{Introdução}

No ano de 2003, a Unesco publicou um documento que abordava como a Ciência deveria ser pensada no século que se iniciava. "A ciência para o século XXI" (UNESCO, 2003) dava orientações sobre como esse campo de conhecimentos deveria contribuir para a sociedade na diminuição de diversas diferenças sociais no Brasil e no mundo. Destacava a necessidade de um novo olhar para o conhecimento científico, compreendido a partir de uma cultura (para) de paz. E, ainda, alertava para os riscos que tanto a ciência como a tecnologia poderiam carregar consigo.

Dentre outras estratégias importantes para o desenvolvimento científico do país, a Unesco (2003) propôs uma que nos chama a atenção: a necessidade de políticas públicas para a popularização da ciência e tecnologia (C\&T). O órgão afirma: "O Estado deve estimular as atividades sistemáticas direta e especificamente relacionadas com o desenvolvimento científico-tecnológico, visando à produção, à divulgação e à aplicação do conhecimento de C\&T" (UNESCO, 2003, p. 18). Expressa, também, a necessidade de possibilitar a compreensão pública e a valorização da ciência pela população, permitindo a sua apropriação, entendendo-a como sua (UNESCO, 2003). Essa apropriação deve atin-

*DOI - 10.29388/978-65-86678-24-6-0-f.93-116 
gir todos os níveis e classes da sociedade, de modo a permitir melhor compreensão sobre o papel da ciência e atrair comunidades que geralmente se consideram "fora do escopo" - como se houvesse um - para a carreira científica. Assim, recomenda-se não apenas um novo olhar, mas uma nova compreensão de quais objetivos a ciência e sua difusão devem ter para esse século.

No ano de 2001, o Governo Federal determinou que no mínimo 30\% dos recursos oriundos do Fundo Nacional de Desenvolvimento Científico e Tecnológico (FNDCT) fossem destinados às regiões Norte, Nordeste e Centro-Oeste do país, com a intenção de "descentralizar" das regiões Sul e Sudeste a produção e difusão de C\&T no Brasil (BRASIL, 2001). Essa descentralização trouxe reflexos para a produção científica e sua popularização nessas regiões, permitindo que os projetos fomentados pelo governo alcançassem lugares que não tinham contato e antes não recebiam determinadas ações governamentais.

Em 2015, o governo brasileiro realizou a última ${ }^{1}$ Pesquisa de Percepção Pública da Ciência e Tecnologia no Brasil (PPCT) (BRASIL, 2015). Os dados desta pesquisa apontam que o brasileiro, em média, possui alto interesse em assuntos que envolvem C\&T. Além disso, também acreditam que a ciência e a tecnologia trazem mais benefícios que malefícios e consideram um aumento dos investimentos nessas áreas algo positivo para o país. Entretanto, o mesmo documento aponta que o acesso à informação científica ainda é baixo no Brasil, com $30 \%$ da população que nunca ou quase nunca obtém informação na mídia mais utilizada para esse fim: a televisão (BRASIL, 2015).

$\mathrm{O}$ acesso a alguns espaços que aproximam a ciência da população como museus, feiras de ciências, semanas de ciência e tecnologia e olimpíadas científicas não ultrapassaram 20\% dos entrevistados (BRASIL, 2015). Comparando com o ano de 2006, houve um aumento de

\footnotetext{
${ }^{1}$ Houve outras três pesquisas anteriores em 1987, 2003 e 2010. A de 1987 foi realizada, inclusive, pelo Conselho Nacional de Desenvolvimento Científico e Tecnológico (CNPq). Essas pesquisas e a abordada no presente texto estão disponíveis para consulta em: http://percepcaocti.cgee.org.br/downloads/. Acesso em 10 nov. 2018.
} 
quase $50 \%$ na visitação a espaços de educação não-formal como museus, jardins botânicos, bibliotecas e feiras de ciências. Os números ainda apontam que nas regiões Norte e Centro-Oeste o aumento no número de visitas em relação ao ano de 2006 é superior a 400\%, enquanto no Nordeste é maior que 100\% (BRASIL, 2015). Portanto, mesmo com os baixos números em acesso a esses espaços, percebemos o impacto de políticas públicas de popularização da ciência no país. É neste sentido que consideramos necessário um olhar para estas ações. Isto pois precisamos compreender quais são seus objetivos e suas expectativas para a sociedade que delas usufrui.

Em âmbito nacional o Conselho Nacional de Desenvolvimento Científico e Tecnológico (CNPq), desde o ano de 2006, realiza chamadas públicas para ações de popularização da ciência que atenderam a diversos estados do país. Em seu site ${ }^{2}$, a instituição descreve que compete a ela promover e incentivar a difusão de dados, informações e conhecimentos científicos e tecnológicos. As chamadas públicas do $\mathrm{CNPq}$ possuem, em determinadas modalidades, três divisões assim caracterizadas: (i) nacionais, (ii) estaduais/distritais e (iii) municipais. Elas podem ser divididas em quatro ações diferentes de popularização da ciência: (a) Olímpiadas Científicas (OCs) internacionais e nacionais; (b) Semanas Nacionais de Ciência \& Tecnologia (SNCTs); (c) Feiras e Mostras de Ciência (FMCs) nacionais, estaduais, municipais e itinerantes e (d) incentivos para Museus e Centros de Ciência (MCCs) em âmbito nacional.

Os projetos contemplados com o apoio do CNPq não necessariamente estão vinculados a Instituições Universitárias. Isto permite a distribuição da verba disponível para diferentes instituições dos estados e municípios da União. Para participar das chamadas deve haver um proponente (pessoa física), organizador(a) da proposta enviada, que possua formação superior ${ }^{3}$. A proposta deve contemplar itens obrigatórios de seu respectivo edital para que tenha avaliação positiva

\footnotetext{
${ }^{2}$ Informações extraídas do site oficial do CNPq e disponíveis em: http://memoria.cnpq.br/ competencias. Acesso em:

${ }^{3}$ A depender modalidade, exige-se pós-graduação dx candidatx.
} 
em julgamento realizado pelos assessores do CNPq.

Além de exigir critérios descritos em cada uma das chamadas públicas, estas possuem um objetivo geral que está intimamente relacionado com o escopo e a ideia de popularização da ciência. Neste contexto existem diversas possibilidades sobre qual o entendimento de "popularização da ciência" e quais propósitos essas ações devem assumir (para) com a população. Portanto, tomamos como mote compreender quais são os objetivos do $\mathrm{CNPq}$ em suas chamadas públicas voltadas à popularização da ciência no país. Para a realização desta pesquisa optamos por uma abordagem do tipo quantitativa/qualitativa e utilizamos a Análise de Conteúdo (BARDIN, 2011) para o estudo desses objetivos. Para compreender melhor conceitos que se encontram relacionados à difusão do conhecimento científico, optamos por uma visão atrelada à cultura científica e à popularização da ciência sob olhares de determinados autores.

\section{A cultura científica, sua apropriação e a popularização da ciência}

Partimos do pressuposto de que uma educação científica de qualidade não deve ensinar somente teorias, leis e conceitos que estão presentes nos conteúdos científicos mas, muito além disto, também deve tratar a ciência como construção humana que, ao longo da histó ria, influencia e é influenciada por outros campos da sociedade (AIKENHEAD, 2009; AULER, 2003; 2007; SANTOS; MORTIMER, 2002). Este olhar holístico para as ciências é objetivo da alfabetização científi ca (AULER, 2003). Entretanto, para Vogt (2003; 2006), o conceito de cultura científica é mais adequado porque além de abarcar o que é pretendido pela alfabetização científica, expõe o processo cultural que é o desenvolvimento científico. No percurso, que vai desde a produção científica até a sua divulgação, a própria população é compreendida como fomentadora da ciência e, por consequência, de cultura científica. 
Uma visão mais ampla a respeito da ciência pode contribuir para que o cidadão reconheça sua posição e importância neste processo. Permite, também, a compreensão de como pode ser feita a ciência, como ela reflete e está presente no cotidiano, como se deve prevenir de seus riscos e como e quando se apropria dela para melhorar a vida. Todavia, para participar desse processo cultural de modo mais pleno, a população precisa ser capaz de se apropriar de conhecimentos e valores presentes na cultura científica, além de posicionar-se criticamente frente a eles.

A apropriação da ciência por parte da sociedade, nesse contexto, não é mais um processo de alfabetização, mas de enculturamento. Quanto mais enculturada cientificamente uma sociedade é, mas ela é capaz de se apropriar dos valores e conhecimentos científicos, e viceversa. De acordo com Vogt $(2003,2006)$, um dos caminhos para promover essa cultura é a comunicação em ciências ${ }^{4}$. Entretanto, ainda restam perguntas: Qual comunicação em ciências tem potencial para permitir uma apropriação da população sobre a ciência? Como essa comunicação pode lograr este objetivo? E quem essa comunicação deve alcançar?

"Divulgação científica" é um termo que pode assumir diversos conceitos a depender do espaço, do tempo e de quem o define. Há mais de 30 anos, Bueno (1985) diferiu difusão, disseminação e divulgação da ciência. O trabalho de difusão da ciência, de suas informações e conhecimento para o público não especializado é compreendido como da divulgação científica, enquanto a disseminação é orientada para pares especialistas. Reis (2002) complementa essa ideia acrescentando os problemas envolvidos na produção desse conhecimento à divulgação.

Atualmente, as definições propostas por Bueno (1985) não são suficientes para contemplar todo o vocabulário que temos sobre essa área. Surgem termos como "vulgarização da ciência" e "popularização

\footnotetext{
${ }^{4}$ Optou-se nesta pesquisa pela utilização da expressão "popularização da ciência" em vez de "comunicação em ciência" ou "divulgação científica", trazidas por Vogt $(2003 ; 2006)$, devido ao fato de o termo estar em consonância com as chamadas públicas do CNPq.
} 
da ciência" que necessitam de uma definição. Ambos os termos já foram utilizados com significados próximos ao que se conceitua por "divulgação científica” atualmente (MASSARANI, 1998). Enquanto, a vulgarização da ciência no Brasil assumiu uma conotação pejorativa devido a "[...] ser associada a ideia de vulgar (do lat. vulgare); relativo ao vulgo; trivial; usual, frequente ou comum" (GERMANO; KULESZA, 2007, p. 9), a popularização da ciência passou a ser compreendida nos países latino-americanos assumindo uma posição na qual:

[...] popularizar é muito mais do que vulgarizar ou divulgar a ciência. É colocá-la no campo da participação popular e sob crivo do diálogo com os movimentos sociais. É convertê-la ao serviço e às causas das maiorias e minorias oprimidas numa ação cultural que, referenciada na dimensão reflexiva da comunicação e no diálogo entre diferentes, orientem suas ações respeitando a vida cotidiana e o universo simbólico do outro (GERMANO; KULESZA, 2007, p. 20, grifo dos autores).

Neste contexto, compreendemos a popularização da ciência não apenas como divulgação científica (SÁNCHEZ MORA; SÁNCHEZ MORA, 2003), mas uma atividade de comunicação que pretende a democratização do conhecimento científico (ROCHA; MASSARANI; PERDERSOLI, 2017; GERMANO; KULESZA, 2007). A popularização da ciência deve ocorrer principalmente em espaços e tempos nos quais os sujeitos têm pouco ou estão excluídos do contato com o conhecimento científico. Pode ser empreendida por meio de políticas públicas que permitem o acesso ao conhecimento e à sua natureza em uma forma dialogada (pela) para a população (LOZANO, 2005), de modo a possibilitar melhor compreensão da construção do conhecimento científico e, assim, promover a sua participação diante das relações críticas entre a sociedade e os seus campos de produção do conhecimento científico.

Haynes (2013) afirma que compete não apenas à escola, mas à comunidade científica, aos meios de comunicação, aos tomadores de 
decisão (políticas públicas) e aos divulgadores da ciência a produção da cultura científica da sociedade. Ações de popularização da ciência são, portanto, fundamentais para promover junto com a escola uma educação científica de qualidade que permita não somente a compreensão daqueles conceitos e leis, mas também melhor entendimento a respeito da natureza do conhecimento científico, desmistificando visões equivocadas sobre a ciência que já se encontram denunciadas na literatura:

[...] concepção empírico-indutivista e ateórica [...][,] visão rígida (algorítmica, exata, infalível...] [...][,] visão aproblemática e a-histórica (portanto dogmática e fechada) [...][,] visão exclusivamente analítica [...][,] visão acumulativa de crescimento linear dos conhecimentos científicos [...][,] visão individualista e elitista da ciência [...][e] imagem descontextualizada, socialmente neutra da ciência [...] (GIL PÉREZ et al., 2001, p. 129-133).

A partir dessas concepções errôneas sobre a natureza do trabalho científico (GIL-PÉREZ, et al., 2001) apresenta-se ao grande público uma ciência que é lugar de uma elite masculina, branca e genial, que realiza um trabalho solitário de laboratório, às vezes com óculos de proteção e jaleco. Distorcemos e por vezes desconsideramos o processo de construção humano da ciência, já citado por Vogt (2003), no qual diversas etnias e gêneros participam (MCCOMAS; ALMAZROA; CLOUGH, 1998) e deixamos de criticar a imposição desse modelo à sociedade atual.

Visões equivocadas podem conferir à ciência uma estética monocultural que tende a afastar uma parcela da população que não se reconhece no escopo apresentado (CITELI, 2000; SOARES, 2004), além de realizar a manutenção de um status quo de desigualdade (LETA, 2003). É por isto que, munida de suas intencionalidades de inclusão, a popularização da ciência tem um grande potencial para reverter, ainda que em pequena escala, este cenário distorcido. Ela pode permitir que os cidadãos se reconheçam como parte integrante dessa 
cultura científica que pode parecer tão distante dele (LEVYLEBLOND, 2006), compreendendo as possibilidades e a importância de sua participação na ciência.

Auler e Delizoicov (2001) realizam uma discussão a respeito dos mitos que são oriundos da concepção asséptica de que a ciência é neutra. Em síntese, para os autores existe uma tendência em compreender que os cientistas, trajados de uma pseudoneutralidade científica, detêm os melhores conhecimentos, meios e instrumentos para resolver determinados problemas da sociedade. A população, crédula de que não detêm conhecimentos necessários para tratar os problemas sociais, abdica de seu direito de participar, ou participa pouco, de decisões que influenciam diretamente a sua vida, com a crença de que o conhecimento científico é o ideal para solucioná-los. Dessa forma, Auler e Delizoicov (2001, p. 132, grifo nosso) concluem:

Nesse ponto, situamos uma das principais considerações em relação às reflexões realizadas neste trabalho: levantamos a hipótese de que, ao reivindicar a divulgação, popularização de conhecimentos, fatos, informações, conceitos, com a honesta justificativa de sua imprescindibilidade para o exercício democrático, pode se contribuir para o estrangulamento pleno da democracia reforçando postulações tecnocráticas. [...] está implícito um risco que, subjacente a isso, haverá 'socialização' [do conhecimento científico e tecnológico], o reforço de mitos e dogmas, construídos historicamente, incompatíveis como o efetivo exercício da democracia.

Complementando estas ideias, Vogt (2006) afirma que o discurso promovido em prol de uma maior participação da sociedade é fácil de ser feito, entretanto faz-se necessário pensar quais mecanismos devem ser adotados para que os cidadãos se representem nessas decisões. Destaca a importância da divulgação científica para atrair jovens às carreiras em C\&T. Afirma, ainda que a dificuldade de atrair esses jovens pode prejudicar o país em seu desenvolvimento científico e tecnológico e cita exemplos de Estados Unidos e Inglaterra, países que 
promoveram ações para atrair esses jovens. Ele destaca eventos como "a criação de museus, organização de feiras e encontros científicos, visitação de universidades e outros recursos atrativos" (VOGT, 2006, p. $1)$.

Se um dos objetivos da divulgação científica, que impacta amplamente a sociedade, é atrair para as carreiras em C\&T, devemos considerar que a popularização da ciência também deve servir a esse propósito, prioritariamente às populações que possuem certo afastamento dos espaços de pesquisa e ensino no contexto brasileiro. Portanto, devemos considerar a popularização da ciência como uma das promotoras do desenvolvimento em C\&T também neste sentido, como também nos fala o documento supracitado "A ciência para o século XXI" (UNESCO, 2003).

Percebamos o quanto cada um dos problemas citados acima está relacionado por meio de uma "situação hipotética". Quando apresentamos a um jovem estudante de escola pública brasileira - considerando todos os problemas que essa escola possui e que se refletem diretamente no seu aprendizado - aquela imagem monocultural, que distorce a cultura científica, tendemos a promover um afastamento, em vista de que ele não se sente pertencente a esta. Seus valores, suas crenças e sua estética não se assemelham nem dialogam com o que é posto. Não o bastante, disto ainda podem resultar dificuldades em desempenhar certas habilidades que são consideradas fundamentais ao cientista (ALCHIN, 2003). Assim, como poderia se tornar parte dessa cultura (científica)? Deste modo, a ciência passa a ser algo a ser admirado de longe, com uma espécie de pureza dogmática.

Essa mesma imagem errônea, implantada na sociedade, faz parecer a esse jovem que a ciência traz a verdade consigo sem a necessidade de questioná-la. Para ele deixa de ser necessário e importante participar de processos de decisão fundamentais à sua vida. Percebemos como este cenário nos é familiar quando observamos os dados que se encontram na referida PPCT (BRASIL, 2015). 


\section{A Análise de Conteúdo aplicada aos editais do CNPq}

As diferentes definições voltadas às práticas de comunicação das ciências (ROCHA; MASSARANI; PERDERSOLI, 2017), como vimos, são dependentes do espaço, tempo e de quem as realiza. Assim, vislumbramos a possibilidade de compreender qual(is) a(s) concepção(ões) de popularização da ciência o CNPq faz uso e quais as intencionalidades compreendem a ela no atendimento à sociedade. Para empreender a análise optamos por utilizar o referencial metodológico de Bardin (2011), de Análise de Conteúdo. De modo sintético, abaixo apresentaremos os passos da pesquisa e em seguida seus resultados. Ademais, entendemos esta pesquisa como quantitativa/qualitativa, na qual o caráter qualitativo se encontra na discussão de aspectos recorrentemente identificados pelo estudo desses editais.

No site do $\mathrm{CNPq}^{5}$ foram encontradas 27 chamadas públicas de popularização da ciência por meio de buscas pelas palavras-chave "Semana Nacional da Ciência e Tecnologia", "Museus e Centros de Ciências", "Olimpíadas Científicas" e "Feiras e Mostras de Ciência”, exatamente os termos utilizados pela própria agência para designar as ações de popularização por ela fomentadas. Determinadas chamadas possuem mais de uma divisão, seja por discriminação de faixas de fomento dos projetos a serem submetidos, por sua abrangência (municipal, estadual/distrital, nacional) ou, ainda, por uma determinada característica, temática ou itinerante (museus), as quais totalizaram 32 editais. Tendo em vista que tais especificidades não alteram os objetivos dos editais, optamos por analisar somente um deles por chamada pública. Assim, os documentos escolhidos perfizeram 27 editais de popularização da ciência.

$\mathrm{Na}$ academia tomamos consciência de que objetivos estão sempre orientados por verbos no infinitivo: investigar, compreender, contribuir, etc. Os editais do $\mathrm{CNPq}$, bem como outros editais, reservam

\footnotetext{
${ }^{5}$ A busca foi realizada no endereço: http://www.cnpq.br/\#void em "bolsas e auxílios", "chamadas" abertas e fechadas.
} 
uma área ao tópico "Objetivos", o que facilitou nosso trabalho na seleção de qual parte do material seria analisada. Assim, optamos por considerar que os índices de nossa análise (BARDIN, 2011) seriam a aparição de verbos conjugados na forma infinitiva nesses tópicos dos editais. Para facilitar o trabalho de reconhecimento dos verbos nos documentos utilizamos o software gratuito IRaMuTeQ ${ }^{6}$. Retiramos de cada edital seu respectivo tópico “Objetivos" e adequamos o material empírico ao software de modo que ele pudesse reconhecer os termos característicos da área de popularização da ciência, a exemplo de "educação não-formal”, como válidos.

Com o uso do software foram encontrados 20 diferentes verbos na forma infinitiva. O verbo mais presente foi "estimular", com 28 aparições, seguido de "selecionar" (19) e "apoiar" (11)7. Considerando ser o verbo no infinitivo nosso indicador de que há um objetivo presente na frase, separamos manualmente cada um dos trechos que se iniciavam por um verbo neste modo de conjugação. Munidos de nossos índices e dos referenciais teóricos, definimos as unidades de registro de nosso estudo: trechos de frases ou frases inteiras que se iniciam pelo verbo na forma infinitiva e que apresentam alguma intencionalidade para a popularização da ciência. São, portanto, unidades de registro temáticas (BARDIN, 2011). O resultado se constituiu de 106 unidades de registro codificadas nos 27 editais de popularização da Ciência do CNPq.

Durante a codificação das unidades de registro reconhecemos 4 unidades de contexto as quais, segundo Bardin (2011)

[...] serve[m] de unidade de compreensão para codificar a unidade de registo e corresponde ao segmento da mensagem, cujas · dimensões (superiores às da unidade de registo) são óptimas para que se possa compreender a significação exacta da unidade de registo. Isto

\footnotetext{
${ }^{6}$ Disponível em: http://www.iramuteq.org/. Acesso em:

${ }^{7}$ Outros verbos encontrados foram: aproximar (3), aumentar (1), colaborar (2), consolidar (3), contribuir (2), desenvolver (2), despertar (1), fortalecer (1), identificar (6), incentivar (7), incrementar (3), obter (1), possibilitar (2), promover (9), propiciar (1), utilizar (1) e valorizar (2).
} 
pode, por exemplo, ser a frase para a palavra e o parágrafo para o tema (BARDIN, 2011, p. 107).

As unidades de contexto identificadas nos editais do $\mathrm{CNPq}$, são: "Educação básica e comunidade escolar", "Jovens e a carreira científica", "Educação não-formal, informal e divulgação científica" e "Percepção pública de ciências e questões sociais". Apoiando-nos no quadro teórico proposto na parte inicial deste texto e, a partir das unidades de contexto, emergiram 17 categorias de análise. Essas categorias e suas descrições se encontram no Quadro 1, abaixo.

Quadro 1: categorias de análise e suas descrições

\begin{tabular}{|c|c|}
\hline Categorias & Descrição \\
\hline $\begin{array}{l}\text { Melhoria do ensino fundamental, } \\
\text { médio e técnico }\end{array}$ & $\begin{array}{l}\text { Compreende eventos de popularização com o objeti- } \\
\text { vo de melhorar a educação básica e o ensino técnico }\end{array}$ \\
\hline $\begin{array}{l}\text { Formação para a comunidade esco- } \\
\text { lar }\end{array}$ & $\begin{array}{l}\text { Promove a formação de docentes, técnicos e alunos } \\
\text { da educação básica }\end{array}$ \\
\hline Letramento Científico & $\begin{array}{l}\text { Incentivo ao letramento científico de alunos da edu- } \\
\text { cação básica }\end{array}$ \\
\hline Produção de Materiais Didáticos & $\begin{array}{l}\text { Fomento à produção de materiais educativos para a } \\
\text { educação formal e não-formal }\end{array}$ \\
\hline $\begin{array}{c}\text { Contribuições às disciplinas escola- } \\
\text { res }\end{array}$ & $\begin{array}{l}\text { Promoção e estímulo em ciências exatas, naturais e } \\
\text { humanas para melhoria da educação básica }\end{array}$ \\
\hline $\begin{array}{c}\text { Aproximação entre instituições e co- } \\
\text { munidade }\end{array}$ & $\begin{array}{l}\text { Promove a aproximação instituições de pesquisa, es- } \\
\text { colas e comunidade }\end{array}$ \\
\hline Aproximação social para ciência & $\begin{array}{l}\text { Incentivo a jovens de camadas sociais diversas ao co- } \\
\text { nhecimento científico e tecnológico }\end{array}$ \\
\hline Estímulo à criatividade e à inovação & $\begin{array}{l}\text { Desenvolvimento da criatividade, inovação e pesqui- } \\
\text { sa entre jovens }\end{array}$ \\
\hline Mulheres na ciência & $\begin{array}{l}\text { Incentivo à participação de meninas e mulheres em } \\
\text { carreiras científicas }\end{array}$ \\
\hline Jovens Talentos & $\begin{array}{l}\text { Seleciona e identifica jovens com habilidades para o } \\
\text { trabalho científico }\end{array}$ \\
\hline Arte e saberes tradicionais & $\begin{array}{l}\text { Valoriza e promove eventos científicos, culturais e } \\
\text { saberes tradicionais }\end{array}$ \\
\hline Espaços não-formais e informais & $\begin{array}{l}\text { Apoio a atividades de popularização da ciência em } \\
\text { espaços não-formais, informais para a sociedade }\end{array}$ \\
\hline $\begin{array}{l}\text { Consolidação, expansão e manuten- } \\
\text { ção }\end{array}$ & $\begin{array}{l}\text { Ampliação e manutenção de programas de divulga- } \\
\text { ção e popularização da ciência no atendimento a po- } \\
\text { pulações }\end{array}$ \\
\hline
\end{tabular}




\begin{tabular}{|c|l|}
\hline Desenvolvimento em C\&T do país & $\begin{array}{l}\text { Popularização e divulgação científica como promo- } \\
\text { toras do desenvolvimento científico, social, humano } \\
\text { e tecnológico do país }\end{array}$ \\
\hline Desigualdades sociais & $\begin{array}{l}\text { Diminuição de desigualdades a partir de avanços em } \\
\text { C\&T }\end{array}$ \\
\hline $\begin{array}{c}\text { Pensamento crítico sobre ciência e } \\
\text { sociedade }\end{array}$ & $\begin{array}{l}\text { Desenvolvimento do pensamento crítico do cidadão } \\
\text { para questões científicas e sociais }\end{array}$ \\
\hline Ciência e Tecnologia & $\begin{array}{l}\text { Reconhecimento da importância da C\&T na socie- } \\
\text { dade }\end{array}$ \\
\hline
\end{tabular}

Fonte: Elaborado pelos autores (2018)

A análise quantitativa dessas categorias, bem como a discussão de algumas delas, é o assunto para o próximo tópico deste capítulo. Consideramos fundamental realizar uma análise qualitativa à luz do referencial proposto a fim de refletir a respeito da concepção de popularização da ciência apresentada pelo CNPq.

\section{Os focos e as concepções da popularização da ciência do $\mathrm{CNPq}$}

\section{Educação básica e comunidade escolar}

No Quadro 2, estão identificadas as categorias criadas a partir da unidade de contexto "Educação básica e comunidade escolar", bem como os números de objetivos relacionados a cada um dos editais do $\mathrm{CNPq}$ e suas ações de popularização.

Quadro 2: Unidade de contexto "Educação básica e comunidade escolar" e suas categorias

\begin{tabular}{|l|c|c|c|c|c|}
\hline \multicolumn{1}{|c|}{$\begin{array}{c}\text { Unid. de contexto/ } \\
\text { Categorias }\end{array}$} & $\begin{array}{c}\text { Feiras de } \\
\text { Ciência }\end{array}$ & Museus & Olimpíadas & $\begin{array}{c}\text { Semanas de } \\
\text { C\&T }\end{array}$ & Total \\
\hline $\begin{array}{l}\text { Educação básica e co- } \\
\text { munidade escolar }\end{array}$ & 6 & 2 & 7 & 14 & 29 \\
\hline $\begin{array}{l}\text { Aproximação entre ins- } \\
\text { tituições e comunidade }\end{array}$ & 3 & 0 & 2 & 0 & 5 \\
\hline $\begin{array}{l}\text { Contribuições às disci- } \\
\text { plinas escolares }\end{array}$ & 0 & 2 & 0 & 8 & 10 \\
\hline
\end{tabular}




\begin{tabular}{|l|c|c|c|c|c|}
\hline $\begin{array}{l}\text { Melhoria do ensino } \\
\text { fundamental, médio e } \\
\text { técnico }\end{array}$ & 1 & 0 & 2 & 0 & 3 \\
\hline $\begin{array}{l}\text { Formação para a co- } \\
\text { munidade escolar }\end{array}$ & 1 & 0 & 1 & 0 & 2 \\
\hline Letramento Científico & 1 & 0 & 2 & 0 & 3 \\
\hline $\begin{array}{l}\text { Produção de Materiais } \\
\text { Didáticos }\end{array}$ & 0 & 0 & 0 & 6 & 6 \\
\hline
\end{tabular}

Fonte: Elaborado pelos autores (2018)

Como podemos observar, dos 106 objetivos de popularização da ciência, 29 se encontram na unidade de contexto "Educação básica e comunidade escolar". Mais de 30\% dos objetivos codificados tinham como pretensão contribuir no desenvolvimento e interesse por disciplinas escolares, em sua maioria a Matemática. A disciplina de Química é citada apenas uma vez na promoção de seu ano internacional, enquanto outras Ciências da Natureza, Humanas e Sociais aparecem apenas como área de concentração a ser promovida.

Dos objetivos que visam contribuir com o aprendizado e o interesse dos alunos em disciplinas escolares, $80 \%$ estão em editais de SNCT, ainda que estes sejam minoria com relação às outras ações de popularização da ciência do CNPq. Fica evidente, também, uma tentativa de que esses eventos contribuam na produção de material didático como jogos educativos, softwares e material impresso para instituições de ensino. A produção desse material, em sua maioria, também está orientado ao ensino de Matemática.

Questões como o letramento científico de alunos da escola apareceram de maneira incipiente: menos de 3\% dos 106 objetivos encontrados nos editais. No que tange à relação entre a popularização da ciência e a comunidade escolar, há uma maior preocupação com os conteúdos escolares, ao passo que o letramento científico surge como uma preocupação secundária. Compreendendo que a popularização da ciência, bem como a divulgação científica, tem um potencial para auxiliar a escola na educação científica de seus alunos (HAYNES, 
2013), destacamos que é necessária uma contribuição não somente em uma educação em ciências, mas também sobre e por ela (SANTOS, 1999).

Essa contribuição vai ao encontro do entendimento de que para alfabetizar cientificamente não basta apenas que os alunos compreendam os conteúdos científicos, mas que eles sejam capazes de agir criticamente (sobre) a partir dele no seu cotidiano. A posição do $\mathrm{CNPq}$, com relação à educação escolar, não parece contemplar essa concepção, uma vez que é forte a preocupação com relação aos conteúdos escolares, especialmente em Matemática.

\section{Educação não-formal, informal e divulgação científica}

Aqui apresentamos as categorias que foram subsidiadas pela unidade de contexto "Educação não-formal, informal e divulgação científica", além de discussões a respeito de aspectos dessas categorias. Assim como no tópico anterior, também constam os números de objetivos encontrados para cada tipo de ação de popularização da ciência. O Quadro 3 serve como referência para a discussão que o sucede.

Quadro 3: Unidade de contexto "Educação não-formal, informal e divulgação científica" e suas categorias

\begin{tabular}{|l|c|c|c|c|c|}
\hline $\begin{array}{c}\text { Unid. de contexto/ Catego- } \\
\text { rias }\end{array}$ & $\begin{array}{c}\text { Feiras de } \\
\text { Ciência }\end{array}$ & Museus & Olimpíadas & $\begin{array}{c}\text { Semanas } \\
\text { de C\&T }\end{array}$ & Total \\
\hline $\begin{array}{l}\text { Educação não-formal, in- } \\
\text { formal e divulgação científi- } \\
\text { ca }\end{array}$ & 6 & 9 & $\mathbf{3}$ & $\mathbf{1 4}$ & $\mathbf{3 2}$ \\
\hline Arte e saberes tradicionais & 0 & 0 & 0 & 5 & 5 \\
\hline $\begin{array}{l}\text { Consolidação, expansão e } \\
\text { manutenção }\end{array}$ & 0 & 0 & 0 & 5 & 5 \\
\hline $\begin{array}{l}\text { Desenvolvimento em C\&T } \\
\text { do país }\end{array}$ & 6 & 0 & 3 & 2 & 11 \\
\hline $\begin{array}{l}\text { Espaços não formais e in- } \\
\text { formais }\end{array}$ & 0 & 9 & 0 & 2 & 11 \\
\hline
\end{tabular}

Fonte: Elaborado pelos autores (2018)

Os editais de SNCT se mantêm como maioria em objetivos 
nessa unidade de contexto. Esses eventos, de acordo com o $\mathrm{CNPq}^{8}$, possuem uma vasta gama de atividades a serem realizadas, o que de certo modo justifica a grande quantidade de objetivos nesses editais. Como podemos observar, os editais de museus acumulam em grande parte a função de apoiar atividades de divulgação científica e popularização da ciência no contexto brasileiro, assumindo mais de $80 \%$ dos objetivos que possuem essa intencionalidade.

Pode parecer óbvio que museus e centros de ciência realizam divulgação científica. Entretanto, o quanto eles são capazes de popularizar a ciência? Devemos perceber que museus, enquanto instituições, têm a potencialidade em dialogar com o seu contexto local, atraindo a população da região e que pode contribuir para a cultura da sociedade em geral (CAZELLI, 2010). O apoio que o CNPq fornece é fundamen tal, à medida que esses espaços trabalham o potencial de popularizar a ciência, especialmente a brasileira.

Chamadas públicas direcionadas para museus e centros de ciências não ocorreram desde o ano de 2013, no qual foram lançados dois editais (de números 85 e 30). Em lugar disso, o CNPq parece investir na "Consolidação, expansão e manutenção" de atividades de popularização nas SNCT. Essa expansão é apresentada, por vezes, com uma intenção de "interiorização" desses eventos de modo a atender municípios e comunidades que se encontram afastadas de instituições que promovem a divulgação e a popularização da ciência.

"Arte e saberes tradicionais", que representa quase 5\% dos objetivos do $\mathrm{CNPq}$, busca dialogar com a ciência por meio de práticas (trans)interdisciplinares com outras formas de conhecimento. Apontam para ideias que pressupomos ser fundamentais para a popularização da ciência: aproximar as ciências, as artes e os saberes tradicionais do contexto no qual as SNCT ocorrem. Esta concepção de popularização da ciência pode permitir uma (re)aproximação entre a cultura científica (VOGT, 2003) com valores, conhecimentos e crenças, desmontando a concepção de que a ciência é um conhecimento que

\footnotetext{
${ }^{8}$ Essas informações se encontram disponíveis no site do CNPq: http://www.cnpq.br/web/ guest/semana-nacional-de-ctii/.
} 
transcende outros. Entretanto, parece ser pouco presente nos editais.

\section{Jovens e a carreira científica}

Nesta seção discutiremos categorias que estão relacionadas com a unidade de contexto "Jovens e a carreira científica", que compreende a maior parte dos objetivos de popularização científica do CNPq. Ao todo são 35 objetivos, que se encontram divididos em 4 categorias, conforme o Quadro 4 apresenta.

Quadro 4: Unidade de contexto "Jovens e a carreira científica” e suas categorias

\begin{tabular}{|l|c|c|c|c|c|}
\hline Unid. de contexto/Categorias & $\begin{array}{c}\text { Feiras de } \\
\text { Ciência }\end{array}$ & Museus & Olimpíadas & $\begin{array}{c}\text { Semanas } \\
\text { de C\&T }\end{array}$ & Total \\
\hline Jovens e a carreira científica & $\mathbf{1 5}$ & $\mathbf{5}$ & $\mathbf{1 2}$ & $\mathbf{3}$ & $\mathbf{3 5}$ \\
\hline Aproximação social para ciência & 0 & 3 & 0 & 0 & 3 \\
\hline $\begin{array}{l}\text { Estímulo a criatividade e inova- } \\
\text { ção }\end{array}$ & 5 & 2 & 1 & 2 & 10 \\
\hline Jovens Talentos & 7 & 0 & 10 & 0 & 18 \\
\hline Mulheres na ciência & 3 & 0 & 1 & 1 & 5 \\
\hline
\end{tabular}

Fonte: Elaborado pelos autores (2018)

Ao contrário dos tópicos anteriores, nas categorias referentes à unidade de contexto "Jovens e a carreira científica" há maior número de objetivos em Feiras e Mostras Científicas e em Olimpíadas Científicas. Absorvendo mais de $33 \%$ de todos os objetivos encontrados, essa unidade de contexto revela a preocupação do $\mathrm{CNPq}$ com relação à identificação, formação e atração de jovens para carreiras relacionadas as ciências.

A categoria "Jovens Talentos" possui a maior quantidade de objetivos nesta unidade. Todavia, tem um caráter de seleção que parece beneficiar somente jovens que possuem certas habilidades que concernem ao trabalho científico. Assim, na definição do que é um bom cientista, ou um jovem talentoso, ao mesmo tempo que seleciona, também exclui. De fato, há certa concordância com Vogt (2006) no que se refere à necessidade de atrair os jovens à carreira científica, mas parte 
da concepção que somente quem já possui “talentos” para ser cientista deve ser um.

Preocupantes são as questões relacionadas ao estímulo de meninas e mulheres para as ciências. Apenas pouco mais de $14 \%$ dos objetivos que relacionam carreira científica a jovens abordam a concepção de que mulheres devem ser incentivadas a fazer ciência. Somente editais de 2017 e 2018 apresentaram explicitamente tais objetivos. Apesar de haver pontos positivos na preocupação do $\mathrm{CNPq}$ a respeito dessa questão, aparece somente em mais um edital a preocupação em desenvolver materiais para o público feminino e nenhum objetivo para outros públicos.

Sem a preocupação explícita em apontar para uma camada social específica, o CNPq exprime a intenção de promover um trabalho que aproxime jovens do conhecimento científico e tecnológico. Elege museus como instituições que são capazes de realizar esse movimento. Na perspectiva de Cazelli (2010) é possível conceber essa instituição como promotora de cultura (científica) promovendo essa (re)aproximação entre jovens de camadas sociais mais desfavorecidas com capital cultural antes inacessível a eles.

\section{Percepção Pública de Ciência \& Tecnologia (PPCT) e questões sociais}

Nesta unidade de contexto, presente no Quadro 5, é discutida a importância da percepção pública de ciência e tecnologia para a construção da sociedade como uma forma de melhoria da qualidade de vida de toda a comunidade. Foi dividida em três categorias que contemplam tal preocupação.

Quadro 5: Unidade de contexto “Percepção Pública de Ciências e Questões Sociais” e suas categorias

\begin{tabular}{|l|c|c|c|c|c|}
\hline \multicolumn{1}{|c|}{$\begin{array}{c}\text { Unid. de contexto/ } \\
\text { Categorias }\end{array}$} & $\begin{array}{c}\text { Feiras de } \\
\text { Ciência }\end{array}$ & Museus & Olimpíadas & $\begin{array}{c}\text { Semanas de } \\
\text { C\&T }\end{array}$ & Total \\
\hline $\begin{array}{l}\text { Percepção Pública de Ciência e e } \\
\text { Questões Sociais }\end{array}$ & $\mathbf{3}$ & $\mathbf{3}$ & $\mathbf{1}$ & $\mathbf{2}$ & $\mathbf{9}$ \\
\hline Ciência e Tecnologia & 0 & 2 & 0 & 0 & 2 \\
\hline
\end{tabular}




\begin{tabular}{|l|c|c|c|c|c|}
\hline Desigualdades sociais & 1 & 1 & 1 & 2 & 5 \\
\hline $\begin{array}{l}\text { Pensamento crítico da ciência } \\
\text { e da sociedade }\end{array}$ & 2 & 0 & 0 & 0 & 2 \\
\hline
\end{tabular}

Fonte: Elaborado pelos autores (2018)

A categoria que contempla ciência e tecnologia deixa evidente a inquietação destes editais quanto à perspectiva da sociedade moderna sobre o tema "Ciência e Tecnologia", ao buscar uma ampliação do conhecimento científico da população em geral e o reconhecimento da ciência como importante para a vida em sociedade. Observando o Quadro 5, a partir dos objetivos identificados, percebemos que este está presente apenas nos editais voltados à implantação de museus. Haynes (2013) nos mostra que o museu é um espaço de educação não formal que pode promover a educação científica de quem o frequenta, ampliando o conhecimento em ciências. Entretanto, compreendemos que não basta unicamente ter acesso a esse conhecimento, mas formar cidadãos que se posicionem criticamente sobre ele.

Essa preocupação pode ser percebida nos editais de Feiras e Mostras de Ciências que têm como objetivos o estímulo à criticidade da população em questões próprias das ciências e que segundo o $\mathrm{CNPq}$

[...] possibilitam um diagnóstico sobre como vem se desenvolvendo o ensino-aprendizagem nos diversos locais do país, de forma a permitir uma intervenção mais adequada que vise o estabelecimento de uma interlocução entre alunos, professores, pais e gestores e a melhoria das condições gerais de ensino (BRASIL, 2018, p. 1) ${ }^{9}$.

Uma preocupação inerente percebida nos objetivos destes editais está relacionada com as desigualdades sociais: para tanto, buscam se utilizar dos eventos científicos para uma melhora na qualidade de vida da população, seja utilizando o conhecimento científico como ferramenta de desenvolvimento de capacidades para a transformação social, bem como para a utilização e a promoção das ciências como uma

\footnotetext{
${ }^{9}$ Disponível em http://www.cnpq.br/web/guest/por-que-popularizar. Acesso em 10 out. 2018.
} 
forma de reduzir tal desigualdade. Todavia, pelos números dispostos em cada um dos quatro quadros de unidades de contexto, percebemos que esses objetivos são preteridos em função de outros.

\section{Últimas considerações}

O caráter seletivo de certos objetivos para a promoção da carreira científica entre jovens corrobora com a concepção de que a ciência é produzida por uma determinada parte da sociedade na qual a maioria dos jovens não se enquadra devido a dificuldades comuns (ALCHIN, 2003). De modo incipiente, os editais abordam questões como as mulheres na ciência, em uma tentativa de aproximação com o público feminino. Um único objetivo em 27 editais orientado para a produção de material voltado a meninas é algo que consideramos extremamente reduzido frente à população feminina que atualmente estuda em escolas públicas pelo país.

Uma (re)aproximação para a cultura científica surge em diversos objetivos propostos pelos editais. Os museus são compreendidos como os principais espaços para a realização dessa ação, mas parece haver um movimento de consolidação e ampliação de Semanas Nacionais de Ciência e Tecnologia, enquanto editais de Museus e Centros de Ciências não são lançados desde 2013. Feiras e Mostras de Ciência, bem como Olimpíadas Científicas, aparecem como espaços que podem contribuir na aproximação de jovens para a carreira científica, ainda que em uma perspectiva seletiva.

Um posicionamento crítico frente a questões que envolvem as ciências é pouco presente nos editais de popularização da ciência devido à prevalência dos conteúdos sobre essas questões. Observamos este fato principalmente na unidade de contexto "Educação básica e comunidade escolar". A relação entre as ciências e outros elementos culturais que tendem a tornar a cultura científica novamente parte da cultura da população (LEVY-LEBLOND, 2006) são objetivados de duas maneiras: (i) na aproximação entre comunidade escolar e instituições 
de pesquisa e (ii) no incentivo à realização de eventos que consideram o contexto no qual ocorrem, o que permite o diálogo entre esses saberes originários da comunidade e da ciência.

Por fim, os editais de popularização da ciência do CNPq se encontram em uma perspectiva na qual os conhecimentos científicos e as habilidades para se fazer ciência ainda possuem espaço privilegiado em detrimento de outras possibilidades, como a alfabetização científica e consequente promoção de uma cultura científica. Ainda que se compreenda a importância dos espaços de educação não-formal para a educação em ciências, esta ainda pode ser entendida em grande parte como o ensino de conceitos, teorias e conteúdos lógicos e matemáticos. Tomando como pressuposto que a popularização da ciência deve aproximar a cultura científica da população e vice-versa, consideramos necessária maior atenção dos objetivos dos editais de fomento a temáticas que dizem respeito à ciência como empreendimento humano e a sua relação com a vida cotidiana das pessoas.

Acreditamos que é necessária uma maior atenção aos eventos fomentados pelo $\mathrm{CNPq}$, para que se possa analisar como os objetivos desses editais se materializam em ações de popularização da ciência, seja na perspectiva exposta em nosso quadro teórico ou não. Desse modo, apontamos que um possível caminho para investigar com mais profundidade questões da popularização da ciência no Brasil é justamente por meio da dedicação a pesquisas que analisem tais ações.

\section{Agradecimentos}

Agradecemos à CAPES e à FAPEMIG pelo apoio financeiro nos estudos da pós-graduação, tempo em que foi concebida esta pesquisa, e aos professores organizadores do presente livro. 


\section{Referências}

AIKENHEAD, G. S. Research into STS science education. Revista Brasileira de Pesquisa em Educação em Ciências, v. 9, n. 1, 2009.

ALCHIN, D. Science Education, v. 87, n. 3, p. 329-351, 2003.

AULER, D. Enfoque Ciência-Tecnologia-Sociedade: Pressupostos para o contexto brasileiro. Ciência \& Ensino, v. 1, 2007.

Alfabetização científico-tecnológica: um novo "paradigma"? Ensaio

- Pesquisa em Educação em Ciências, v. 5, n. 1, 2003.

BARDIN, Laurence. Análise de conteúdo. São Paulo: Edições 70, p. 229, 2011.

BRASIL. Lei $\mathrm{n}^{\circ}$ 10.971, de 14 de fevereiro de 2001. Acresce dispositivos ao Decreto-Lei $n^{\circ} 719$, de 31 de julho de 1969, para dispor sobre o financiamento a projetos de implantação e recuperação de infraestrutura de pesquisa nas instituições públicas de ensino superior e de pesquisa, e dá outras providências. Diário Oficial da União, Atos do Poder Legislativo, Brasília, DF, 14 de fevereiro de 2001. Disponível em: <http://www.mpm.mp.br/referenciasbibliograficas-documento-juridico/.> Acesso em: 26 set. 2018.

Percepção pública da ciência e tecnologia: Ciência e tecnologia o olhar dos brasileiros. Sumário Executivo. Brasília, DF, 2015.

BUENO, W. C. Jornalismo Científico. Ciência e Cultura, v. 37, n. 9, p 1421427, 1985.

CAZELLI, S. Jovens nos museus: quem são, aonde vão e com quem visitam? In: DALBEN, A.; et al. (Orgs.). Convergências e tensões no campo da formação e do trabalho docente. Belo Horizonte: Autêntica, 2010. Disponível em: $<$ https://perdigital.files.wordpress.com/2011/04/livro 5.pdf.> Acesso em: 20 out. 2018.

CITELI, M. T. Mulheres nas ciências: mapeando campos de estudo. Cadernos Pagu, v. 15, p. 39-75, 2000.

GERMANO, M. G.; KULESZA, W. A. Popularização da Ciência: uma revisão conceitual. Caderno Brasileiro de Ensino de Física, v. 24, n. 1, p. 7-25, 2007. 
GIL PÉREZ, D. et al. Para uma imagem não deformada do trabalho científico. Ciência \& Educação, Bauru, v. 7, n. 2, p. 125-153, 2001.

HAYNES, E. R. Los museos de ciencia em la sociedad de la información y el conocimento. In: El Museo y la Escuela, Medelín: Claúdia Aguirre Ríos, 2013. p. 147.

LETA, J. As mulheres na ciência brasileira: crescimento, contrastes e um perfil de sucesso. Estudos Avançados, v. 17, p. 271-284, 2003.

LEVY-LEBLOND, J. Cultura Científica: Impossível e Necessária. In: VOGT, C. Cultura Científica: Desafios. São Paulo: FAPESP, 2006. p. 232.

LOZANO, M. M. H. Hacia um nuevo contrato social: la popularización de la ciencia y la tecnologia. 2005. Dissertação (Mestrado em Filosofia da Ciência) - Instituto de Investigaciones Filosóficas, Universidad Nacional Autónoma de México, Ciudad de México, 2005.

MASSARANI, L. A divulgação científica no Rio de Janeiro: Algumas reflexões sobre a década de 20. 1998. 127 f. Dissertação (Mestrado em Ciência da Informação) - Instituto Brasileiro de Informação em Ciência e Tecnologia, Escola de Comunicação, Universidade Federal do Rio de Janeiro, Rio de Janeiro, 1998.

MCCOMAS; W. F.; AMALZROA, H.; CLOUGH, M. P. The nature of science in science education: an introduction. Science \& Education, v. 7, p. 511$532,1998$.

REIS, J. Ponto de vista. In: MASSARANI. L.; MOREIRA, I. de C.; BRITO, F (Orgs.). Ciência e Público: caminhos da divulgação científica no Brasil, Rio de Janeiro: Casa da Ciência - Centro Cultural de Ciência e Tecnologia da Universidade Federal do Rio de Janeiro, 2002. p. 231.

ROCHA, M.; MASSARANI, L.; PEDERSOLI, C. La divulgación de la ciencia em América Latina: términos, definiciones y campo académico. In: MASSARANI, L. et al. (orgs.). Aproximaciones a la investigación em divulgación de la ciencia em América Latina a partir de sus artículos académicos. Rio de Janeiro: Fiocruz - COC, 2017. p. 208.

SÁNCHEZ MORA, A. M.; SÁNCHEZ MORA, C. Glosario de términos relacionados com la divulgación: uma propuesta. El Murciélago, p. 9, jan. 2003. Disponível em: <http://www.redpop.org/wp-content/uploads/2015/06/Apro- 
ximaciones-a-la-investigaci\%C3\%B3n-en-divulgaci\%C3\%B3n-de-la-cienciaen-Am\%C3\%A9rica-Latina-a-partir-de-sus-art\%C3\%ADculos-acad \%C3\%A9micos.pdf.> Acesso em: 05 ago. 2018.

SANTOS, M. E. Encruzilhadas de mudança no limiar do século XXI: coconstrução do saber científico e da cidadania via ensino CTS de ciências. In: Encontro Nacional de Pesquisa em Educação em Ciências, 2., 1999, Valinhos. Atas... Valinhos, 1999.

SANTOS, W. L. P. dos; MORTIMER, E. F. Uma análise de pressupostos teóricos da abordagem C-T-S (Ciência-Tecnologia-Sociedade) no contexto brasileiro. Ensaio - Pesquisa em Educação em Ciências, v. 2, n. 2, 2002.

SOARES, A. H. de M. A química e a imagem da ciência e dos cientistas na banda desenhada: uma análise de livros de B. D. e de opiniões e interpretações de investigadores, professores de C.F.G. e alunos do $3^{\circ}$ ciclo. 2004. Dissertação (Mestrado em Química - Especialização em Ensino) - Universidade do Minho, Braga, Portugal, 2004.

UNESCO. A ciência para o século XXI: uma nova visão e uma base de ação: Brasília: UNESCO ABIPIT, 2003.

VOGT, C. A Espiral da cultura científica. ComCiência, Campinas, jul. 2003. Disponível em: <http://www.comciencia.br/dossies-1-72/reportagens/cultura/cultura01.shtml.> Acesso em: 08 set. 2018.

. O desafio de divulgar ciência: entrevista. Jornal da Unicamp, Campinas, out./nov. 2006 Entrevistador: L. Sugimoto. Disponível em: $<\underline{\text { http:// }}$ www.unicamp.br/unicamp/unicamp_hoje/ju/outubro2006/ ju342pag11.html.> Acesso em: 08 set. 2018. 